\title{
The Interdivisional Group of Computational Physics
}

The Computational Physics Group was established to provide a forum for the discussion of all subjects which concern the use of computers in physics. In the past decade, the computer has become an important and often essential tool in such branches of science as astrophysics, plasma, solid state and high energy physics to mention but a few, and it is clear that this trend will extend to other branches in the future. Although the physical problems in these fields are by their nature rather different, there is often considerable overlap in the difficulties encountered in computational and data handling methods, and in the numerical methods used. For example, astrophysics, meteorology, and solid state physics require the solution of partial differential equations in three dimensions; high energy physics, meteorology and space physics require the recording and reduction of very large amounts of experimental data.

A proposal was put forward to the EPS Council in February 1970, to establish an Interdivisional Group of Computational Physics (see Euro- physics News No. 8, March 1970), because it was felt that such a group could best provide the background for an exchange of views on computational problems between physicists of different fields, not only mathematical problems, but data handling and the use of computers in general as well.

The interdivisional approach has many advantages, such as making it possible to compare the computational aspects of a variety of physical problems, which may lead to the development of more generally applicable methods and systems. The approach of physicists in one field can be compared with that of physicists in other fields and each sector might reveal useful applications to the other. Unlike some other groups of the EPS which were in existence in another form prior to becoming a division of the EPS, the Computational Physics Group is newly founded. This fact, coupled with the principal aim of the group, viz. to establish and reinforce contact between different branches of physics, means that the main initial effort will be put on

\section{H. Grote Secretary}

holding meetings - conferences, workshops and summerschools stimulating the exchange of staff and students between laboratories, and encouraging the development of appropriate channels for the publication of papers in computational physics in Europe. An important step forward has been the recent extension of the scope of the Physics Communications Journal which will now accept papers describing applications of computers to physics.

The main effort has consisted of organizing an international conference on computational physics. A first attempt to set up a conference in Paris in September 1971 had to be abandoned, however, because of lack of financial resources.

Now, since November 1970, preparations are going ahead to hold a conference at CERN, Geneva, in April 1972, with the title "First European Conference on Computational Physics" and the theme "The Impact of Computers on Physics". This conference is meant to be the first in a series of perhaps biennial conferences organized by the Computational

\section{Science Editor}

A full-time Editor attached to the Main Secretariat in Geneva is required by the European Physical Society to take charge of publications. The work associated with this post will include the editing of Europhysics News and the development of this publication and other forms of information and communication with members of the Society.
English is required as first language, a physics background and several years experience in scientific or technical journalism. A knowledge of other European languages would be an advantage.

A monthly salary of not less than Sw.Fr. 3.500. - is envisaged.
Candidates should write in confidence stating their experience and including examples of the work for which they have been responsible, to the :

\section{Executive Secretary \\ European Physical Society \\ РОВ 309 \\ CH - 1227 Carouge-Geneva \\ Switzerland}


Physics Group. Well-known scientists will give their views on the role the computer has played in their field in the recent past, and is likely to play in the near future. Following the aim of the Group to interest physicists in the computational problems of other branches, the invited review papers will be given in plenary sessions throughout the period of the conference. In addition, more specialized contributed review papers will be presented in parallel sessions. It is a pleasure to acknowledge the help of CERN in realizing this project. Further details and an application form will be found on p. 7 of Europhysics News, Vol. 2, No. 3. During the conference, the Computational Physics Group will hold its first business meeting, at which the members of the Group will participate in the various administrative activities necessary for the foundation of the Group (acceptance of rules, election of a board, etc.) and will, in addition, have discussions on the future programme of the Group. The response to the preliminary announcement of the conference and to the EPS questionnaire concerning group membership has so far been very encouraging.

Meanwhile, until the conference in April 1972, the affairs of the Group are being taken care of by the interim board consisting of :
H. Bross, Munich
E. Clementel, Bologna
K. Differt, Stuttgart
M.R. Feix, Nancy
H. Grote, Geneva (Secretary)
E. Knighting, Bracknell
G.R. Macleod, Geneva (Chairman)
G.I. Marchuk, Novosibirsk
C. Moser, Orsay
C.L. Pekeris, Rehovoth
K.V. Roberts, Abingdon
R. Thirlby, Newcastle-on-Tyne
A. Vaciago, Rome
L. van Hove, Geneva
L. Verlet, Orsay

\section{Computer Documentation: Easy Access to Scientific Knowledge}

\section{Steinacker ESRO}

The European Space Research Organization (ESRO) maintains a large computerized documentation service for its Member States. The system which, since 1969 , has been operating via an on-line dialogue interrogation program provides an extensive coverage of scientific and engineering literature even outside the confines of space research, and is steadily enlarging its terminal network throughout Europe. Furthermore considerable efforts are made to facilitate the practical exploitation of the system by the user community.

\section{Coverage of Literature}

The ESRO/ELDO Space Documentation Service was originally based on the NASA file, made available to ESRO under a generous exchange agreement. NASA started to collect document references (see Fig. 1) as early as 1962 and by now this collection has risen to over half a million items. About half consists of 'unpublished' material (NASA, US Government and industrial reports) which is very difficult to locate in Europe but can very easily be retrieved through the computer and is also available on microfiche or as hard copy from ESRO in Paris.

This collection of unpublished material is particularly important in helping to broaden substantially the basis of knowledge in most fields of natural science and engineering be- cause it provides access to the results of advanced studies carried out in space research programmes.

The other half of the NASA collection is provided by the American Institute of Aeronautics and Astronautics (AIAA) which regularly scans about 1500 periodicals for articles falling within the very broad scope of NASA interests. Bibliographic references are extracted from the original literature only and not from abstracts journals. The NASA file thus constitutes an abstracts journal on magnetic tape, and the computer printout (Fig. 1) contains not only the title but also a short notation of content and a list of scientific terms (descriptors) identifying the subjects treated in the document.

As the 1500 journals scanned by the AIAA do not cover a sufficiently broad section of the general literature, ESRO is adding other magnetic tape services to the collection. Among the services already available or shortly to be provided are the METADEX tapes produced by the American Society of Metals, a collection which since early 1969 has grown by about 25000 references per year, the US Government Research and Development Reports (growth rate about 50000 items per year) and the Engineering Index (growth rate about 60000 items per year).

Thus the collection of bibliographic references maintained by the ESRO/ ELDO Space Documentation Service

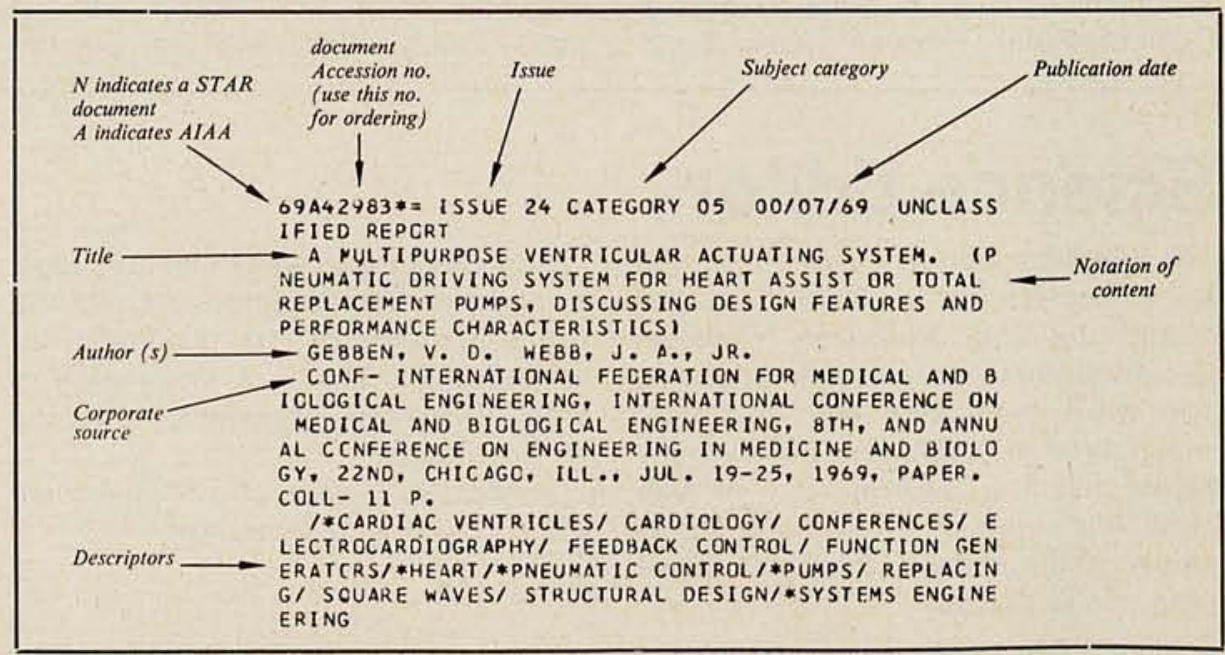

